\title{
Vignettes: Implications for LIS Research
}

\section{Allison Benedetti, John Jackson, and Lili Luo}

\begin{abstract}
Vignettes, brief descriptions of fictional characters and situations, serve as a tool to study people's lives, perceptions, beliefs, and attitudes about specific situations. Although not widely used in library and information science (LIS) research, vignettes can depersonalize responses to controversial situations or behavioral responses related to abstract concepts when employed in focus groups, in-depth interviews, or surveys. We use two research projects, one focused on the Association of College and Research Libraries' Framework for Information Literacy for Higher Education and one on the vocabulary used to describe library services, to discuss the strengths of vignettes and implications for LIS research.
\end{abstract}

Vignettes are "short stories about hypothetical characters in hypothetical circumstances, to whose situation the interviewee is invited to respond." ${ }^{11}$ Researchers can use vignettes as a methodological tool in focus group, in-depth, or survey interviews during which interviewees are invited to draw upon their own experience to provide perceptions, opinions, beliefs, attitudes, and diagnostic predictions about how the fictional character in the vignette will behave. ${ }^{2}$ They are often appropriate in such cases when observing or placing an individual in a particular context is not possible for logistical or ethical reasons. ${ }^{3}$ Approximating real-world situations, vignettes allow features of the context to be specified so that interviewees can make normative statements about a set of social circumstances rather than providing their responses in a vacuum. ${ }^{4}$ Here we discuss this research method and its implications for library and information science (LIS) research, particularly for academic libraries.

Vignettes are often presented as written narratives that interviewees can read. Other forms of presentation, such as artwork and photographs, ${ }^{5}$ videos, ${ }^{6}$ and PowerPoint slides, ${ }^{7}$ are also possible. Some researchers favor video recordings because they allow direct observation to capture more of the ambiguities surrounding everyday life and individual behavior. ${ }^{8}$ However, producing video vignettes is more costly and time consuming.

Vignettes must include sufficient detail to allow interviewees to visualize the hypothetical circumstances as actual situations. Therefore, researchers should specify the situational elements of a vignette carefully, including giving the main character a

Allison Benedetti is Librarian for Advanced Research and Engagement in the UCLA Library; e-mail: abenedetti@library.ucla.edu. John Jackson is Outreach E Communications Librarian in William H. Hannon Library at Loyola Marymount University; e-mail: john.jackson@lmu.edu. Lili Luo is Associate Professor in the School of Information at San Jose State University; e-mail: lili.luo@sjsu.edu. (C2018 Allison Benedetti, John Jackson, and Lili Luo, Attribution-NonCommercial (http://creativecommons.org/licenses/by-nc/4.0/) CC BY-NC. 
name. Following each vignette, the researcher may ask either an open-ended question or a closed question with a set of response categories from which interviewees may choose. Probes, when necessary, may allow interviewees to elaborate on their responses.

Boxes 1 and 2 contain examples of vignettes. The example in Box 1 is from Finch's survey study documenting the normative beliefs about obligations between relatives to provide practical or material support for each other. ${ }^{9}$ In that study, Finch used the vignette in structured survey interviews and asked the following closed question with pre-established response categories. The example in Box 2 is from the study by Fischer et al. study about user involvement in drug treatment decision making. ${ }^{10}$ It was part of a semistructured interview followed by an open-ended question.

\section{BOX 1}

Jim and Margaret Robertson are a married couple in their early forties. Jim's parents, who live several hundred miles away, have had a serious car accident and they need long-term daily care and help. Jim is their only son. He and his wife both work for the Electricity Board and they could both get transfers so they could work near his parents.

Question-From the card, what should Jim and Margaret do?

- Move to live near Jim's parents

- Have Jim's parents move to live with them

- Give Jim's parents money to help them pay for daily care

- Let Jim's parents make their own arrangements

- Do something else (specify):

- Don't know

\section{BOX 2}

Davie is 19 . He started smoking hash when he was 14 and soon moved on to speed and E. When he was 17 , he first tried smoking heroin. After a year, he started injecting and his habit quickly grew to $£ 80$ a day. He was injecting so often that he eventually lost his job and now his girlfriend has left him. Davie thinks he is no longer in control of his drug use and decides to seek help.

- Question -What do you think Davie will do?

Vignettes may consist of single snapshots of fictional scenarios or a series of stages as the scenarios unfold. The latter are commonly referred to as developmental vignettes. The development of the different stages may be either fixed or interactive. If developmental vignettes include fixed stages, the researchers control the development of the scenarios and the interviewees' responses do not influence how the scenario unfolds. Interactive developmental vignettes, on the other hand, allow interviewees to select potential courses of action from a list of options; their selections serve to determine how these vignettes progress. ${ }^{11}$

Fleming and Stalker group vignette-based research into three broad categories: exploratory, predictive, and experimental. ${ }^{12}$ In exploratory studies, researchers usually use vignettes in qualitative interviewing (examples: focus groups, in-depth interviews) to explore topics conceptually and to stimulate discussions about them. The relatable context provided by vignettes result in more targeted and meaningful responses than conventional qualitative interviewing techniques, helping to achieve insights into the social components of interviewees' interpretive frameworks and perceptual processes. ${ }^{13}$ When vignettes are employed in a predictive capacity (often in psychological studies), interviewees respond by answering a closed question with structured responses. Statistical analyses are then conducted to describe the variations in responses and 
examine their association with independent variables. ${ }^{14}$ In factorial research designs, researchers may use vignettes as experimental stimuli, modifying parts of the vignettes to produce multiple versions representing variables of the same vignette concept. By randomizing study participants to each unique version, researchers isolate the influence of each factor (or each variation) on participants' responses. ${ }^{15}$

Researchers believe that vignettes provide a valuable research tool for studying people's lives, perceptions, beliefs, attitudes, and meanings about specific situations. ${ }^{16}$ According to Schoenberg and Ravdal, the storytelling nature of vignettes is relaxing, pleasant, and interesting and may reduce feelings of being overburdened by the interview process. ${ }^{17}$ Hughes and Huby perused the literature and identified the following practical advantages of vignettes: ${ }^{18}$

- Vignettes are less expensive and can be conducted more quickly than observational studies.

- During qualitative interviews, vignettes provide a useful focus for discussion and can act as a stimulus for group discussions.

- The content and staging of vignettes can be defined and standardized to enable all participants to respond to the same stimulus and, therefore, lead to more uniform data.

- Vignettes do not necessarily require participants to have in-depth knowledge of the topic under study and may be used to elicit participants' automatically generated meanings.

- By asking interviewees to assume the roles of vignette characters, vignettes can help desensitize sensitive or difficult topics (such as sexual aggression or mental illness), distance interviewees from them, and reduce the influence of socially desirable responses.

In constructing vignettes, plausibility is a crucial factor. Vignettes viewed as highly plausible are more likely to perform accurately and sensitively and thus yield rich data from interviewees. Implausible vignettes can result in negative reactions from participants, including feelings of confusion, distress, embarrassment, anger, or disinterest. ${ }^{19}$ Researchers may consider conducting focus group interviews to determine the most plausible scenarios to be used in vignettes. Extensive pretesting is also critical to ensure plausibility.

In developmental vignettes, interviewees may give responses that deviate from the way the vignette unfolds, causing them to feel embarrassed or to feel that they have given a "wrong" answer, which may result in their giving more socially acceptable answers in subsequent questions. ${ }^{20}$ To alleviate this concern, Finch pointed out that "very careful question wording to minimize the impression that anyone had got it wrong may be particularly important." ${ }^{21}$ Researchers need to make it clear to interviewees that their responses may differ from the progression of the scenario and that these differences are a desired aspect of the research. ${ }^{22}$

Another consideration in vignette construction is how many vignettes one can use and how complex each one should be. Interviewees must be able to follow and understand vignettes readily; thus, vignettes must be internally consistent and not so complex that interviewees lose the thread. ${ }^{23}$ The number of vignettes to use is dependent on the purpose of the study and the number of topic elements and their combinations the researcher is investigating. For simpler and shorter vignettes designed to explore a limited number of elements, the chances of the interview including the full range of all possible combinations of elements are higher. For example, if a vignette contains two variables (for instance, gender, political party) and that each has two attributes (gender: female, male; political party: Democrat, Republican), the full range of all possible combinations of elements is four. Including four vignettes in one interview is both reasonable and feasible. 
Hughes and Huby discussed the importance of understanding study participants to properly construct vignettes. Because participants must respond from the perspective of the vignette character, any disjuncture between the participants' actual experiences and those of vignette characters can result in problems. In addition, if any of the participants will be people with learning difficulties, researchers may find it beneficial to restrict vignettes to single words and short sentences. Ultimately, however, the effective use of vignettes is contingent upon the nature of the research question, the characteristics of the study participants, and the ethical and practical issues that permeate the research process. ${ }^{24}$

In the past half-century, researchers have used vignettes extensively in anthropology, ${ }^{25}$ psychology, ${ }^{26}$ sociology, ${ }^{27}$ and nursing and public health. ${ }^{28}$ However, in LIS research, the use of vignettes has been minimal. This lack of awareness of vignettes as a methodological tool in LIS research has served as our motivation to introduce this method to LIS researchers and to discuss its implications for our field.

\section{Applications for Vignettes in LIS Research}

Few published examples of the use of vignettes in LIS research exist: Urquhart and Crane used vignettes to elicit information-seeking habits and perception levels among nursing staff at a health college in the United Kingdom. ${ }^{29}$ Connor described and recommended the use of vignettes in training clinical researchers. ${ }^{30}$ Walden compiled a sample of strategies and methodologies, including vignettes, that may be used with focus groups to increase or enhance participant interactions. ${ }^{31}$ Walden also suggested possible but general library connections for various methods drawn primarily from medicine and social science research. Other researchers conducting LIS studies have used similar narratological methods to study student perceptions of information literacy. ${ }^{32}$ However, these researchers did not explicitly use vignette-based methodologies.

Because vignettes are helpful in depersonalizing sensitive topics and encouraging respondents to talk more openly, they could be potentially useful for researching the attitudes and behaviors of scholars related to practically any area in which librarians are curious about users' behaviors and habits, including publishing, copyright, and open access practices. Vignettes could also be used with students to teach about or demonstrate concepts related to plagiarism and academic integrity. User experience and web design practices have long involved the use of personas or archetypes to evaluate interface designs and functionality; thus, vignettes could have a place in augmenting these practices, perhaps in remote or online usability studies. Scenario planning, which involves the construction of hypothetical future states to imagine the impact and needs of alternative directions, has been used successfully in library strategic planning. ${ }^{33}$ While similar in its use of a hypothetical narrative, vignettes differ from scenario planning, specifically in their aim to elicit a more honest response, rather than presenting multiple potential situations and asking a group to plan for and weigh the impact of each.

In the following two examples, we have suggested more specific applications of the vignettes method for LIS research based on our experiences in developing research projects for the 2014 Institute for Research Design in Librarianship, an intensive summer program dedicated to training LIS professionals in various qualitative and quantitative methodologies. Both examples - the first from a small liberal arts college and the second from a large research university-include a discussion of the topic of the research project, the rationale for choosing vignettes as the research method, the study design, and reflections on this methodological experience. The two examples were authored by two different librarian researchers. Through these examples, we hope to illustrate the versatility of vignettes as a data collection tool and to suggest other potential uses in LIS research. 


\section{Example 1: Vignettes in Information Literacy Assessment}

Topic. Threshold concepts have emerged in recent years as one additional way to conceptualize information literacy. Most notably for academic librarians, threshold concepts have served as the pedagogical foundation for the Framework for Information Literacy for Higher Education. ${ }^{34}$ Jan Meyer and Ray Land, who first developed the idea, define threshold concepts as "portals" that represent "a transformed way of understanding, or interpreting, or viewing something without which the learner cannot progress." ${ }^{35}$ Within the context of library instruction, these threshold concepts include scholarship as conversation and information has value, problematic claims with which students must grapple on their path toward a more complex understanding of information literacy. ${ }^{36}$

The impetus for a potential project using vignettes to examine threshold concepts for information literacy arose from two questions. The first concerned the need for assessment tools: How does one measure a nebulous idea like information has value, especially given that threshold concepts are by definition integrative and troublesome and are more akin to tacit knowledge than explicit knowledge? A student who exists upon a spectrum between lack of understanding and full emergence could offer a wide range of responses to questions such as "Does information have value?" - none of which would necessarily be more correct than any other. Furthermore, how could we tell if the answer given is evidence of true understanding or simply what is socially or academically acceptable?

The second question concerned the selection of the specific concepts outlined in the Framework. What seemed apparent at the time the author began this research was that the final six concepts outlined in the Framework were far from exclusive; thus, the threshold concepts selected for the final draft were more indicative of the concepts that librarians value most rather than an exhaustive list. This led to the second question: How do students value these threshold concepts? The answer could help in determining the best strategies for designing a thresholds-based approach to information literacy in the classroom.

Methodology Rationale. As previously noted, vignettes provide an opportunity to study normative material, which is often difficult to capture using more direct questioning methods in in-depth interviews and focus groups (example: "What would you do if..."). They allow the investigator to explore perceptions, attitudes, and beliefs about material that may be sensitive, private, illegal, or, in the case of threshold concepts, difficult to define. Furthermore, vignettes "allow investigators to gain insight into their participants' interpretive framework and perceptual processes by placing the participants within a situation that encourages them to explicate their social/cultural/group norms in order to respond to the characters in the [vignette]." ${ }^{37}$ The author sought to determine to what extent undergraduate students value the threshold concepts outlined in Framework, concepts students will have internalized to varying degrees. Knowing their responses to direct questions about these concepts might be muddled by their knowledge of certain expected behaviors, anthropologist, research methods expert, and Institute for Research Design in Librarianship instructor Greg Guest recommended using a vignettes-based survey. ${ }^{38}$

Procedures and Design. The author created a fictional story that outlined a typical undergraduate research experience. In the story, Jenny, an environmental studies major, is working on a semester-long project exploring the health effects of genetically modified crops on humans and livestock. As Jenny progresses from the initial exploration phase of her research to her final presentation, she encounters six dilemmas, each corresponding to one of the threshold concepts detailed in the Framework. The story is divided into six segments, one for each dilemma. At the end of each segment, the author asked participants a series of semistructured questions to elicit their opinions on Jenny's work, their advice, and their assumptions about what most students would 
do in a similar situation. The proposed study was reviewed and approved by the campus's Institutional Review Board (IRB).

For example, to explore the concept information creation as a process, participants were read the following vignette:

Jenny's professor has asked all the students in the class to experiment with different ways of presenting their final project. For example, students don't have to submit a traditional research paper and instead can choose to do something different as long as the information is communicated effectively. Jenny isn't quite sure what would be the best way to present her findings.

Q1: If you can, list for me some of the ways that Jenny could present her findings to the professor.

Q2: How would Jenny gather information on her topic differently depending on whether she decides to [insert responses from Q1]?

Q2.1: [probing for value]

Q1 was designed to prime participants to think about different ways of presenting information (such as PowerPoint, digital story, lecture). Q2 asked participants to consider the relationship between information creation and the final information product. However, the intent of the probing that occurs in Q2.1 was to elicit value statements. For example, if a student mentioned that less research is necessary for a PowerPoint presentation, the investigator could follow up with questions about the merit of PowerPoint as a communication vehicle and the amenability of certain formats to certain types of information.

According to Guest, Namey, and Mitchell, only six in-depth interviews are necessary to reach saturation with a relatively homogenous sample. ${ }^{39}$ The author initially sought to oversample and interview twenty undergraduates, five from each class, purposely sampled to achieve maximum variation by class year. However, given the time and resource constraints of the spring semester, doing so was not feasible; so the author interviewed only fifteen students. The transcribed interviews were coded, using inductive thematic analysis to identify students' values, attitudes, and perceptions about research-related threshold concepts.

Results. The student responses revealed both anticipated and unexpected trends. For example, after analyzing the responses to the questions used in an example above (those that align with the threshold concept information creation as a process), the author found that many participants held the belief that creating visual information products (such as slide presentations or poster boards) requires less effort and/or the created product should be simplified, general, or informal in nature. This finding should come as no surprise to instructors. However, respondents did not always agree on which stage of the research and information production process required less effort: whether it was the gathering information stage, the building an argument stage, or the creation and dissemination stage. This finding could be potentially important for instructors when speaking with students about the time and effort required to, for example, create a PowerPoint presentation based on traditional research methods.

Again, in response to the same vignette, some respondents noted the one-to-one relationship between the qualities of the desired information product (examples: slide presentation, research paper, chart, or diagram) and the qualities of the information used to create the product. For example, one participant stated that creating interactive products requires gathering sources that are likewise interactive in nature. Many respondents noted the role that searching for images plays in the creation of visual products. Once again, this finding should not come as a surprise to instructors, but 
it does highlight a common perception among the participants: that the information creation process is a type of bricolage: for example, if the desired product is textual, one must gather and piece together textual sources; if the desired product is visual, one must gather visual sources. With this understanding of student behavior, how could librarians adapt their approach to information literacy instruction to potentially counter this misguided perception of the research process? Having some insight into the beliefs and attitudes that students possess toward the information-gathering process can prepare reference and instruction librarians to identify when those beliefs may be "in play" during conversations with student researchers at the reference desk or in the library classroom.

Reflections. The most difficult aspect of using vignettes was the development process. The author needed to create a story that not only encompassed all six threshold concepts but also embodied content to which undergraduates could relate regardless of their class level or area of study. After some initial feedback in the pretesting phase, the author determined that an undergraduate researching the effects of genetically modified organisms, while specific to the sciences, was the type of project any student would find familiar: namely, a project that required students to research recent publications and public opinion about a well-known topic.

During the pretesting, students were asked to listen to earlier drafts of the vignettes and then not only to respond to questions but also to give their opinions about the way the story was told (vocabulary, narrative arc, and so on). This was essential to creating a story free of jargon, leading questions, and confusing concepts. For example, the author asked participants to discuss their thoughts on how information should be published. In the initial draft, the author used the term personal website and quickly discovered that this meant different things to different people (examples: a Tumblr page, a LinkedIn profile, Facebook). In some cases, the term was not applicable, as one respondent noted: "I don't think many people have personal websites." Instead, the term professional website more accurately brought to mind the type of website the author wanted participants to envision (that is, an online portfolio or curriculum vitae), even if they did not own one themselves. In crafting vignettes, one should consider pretesting multiple versions or convene a focus group to draft a story collaboratively. Of course, the essential character and constitution of the story would likely differ significantly, depending on the composition of the focus group (whether it consisted of librarians, teaching faculty, or students).

Finally, many of the participants seemed tied to the subject of the first vignette (not discussed here) in the study, which concerned the value of authority and credibility. A number of participants continually referred to the concept of authority throughout the interview as if this were the primary threshold concept under investigation. This tendency was not revealed in pretesting. Therefore, future LIS researchers that incorporate developmental vignettes composed of a single narrative arc should emphasize the change in topic/focus when moving from one vignette to the next.

\section{Example 2: Vignettes in Library Services Marketing}

Topic. Libraries are in the midst of great change in service models and building space usage. Part of this shift includes the language used to talk about the services offered. Do the words reference or reference desk effectively and accurately convey what librarians offer? This example is a case study from a large research university's library. Although the staff at the library have been using research help, assistance, and consultation more in signage and marketing, these terms may not carry the appropriate message and connotations. Interpretation may also differ by user population (such as sciences vs. humanities, undergraduate vs. graduate student or faculty). 
Within the health sciences, many positions are termed research informationist or informationist rather than reference librarian or other more traditional titles. ${ }^{40}$ Although much literature exists on the changing roles of librarians, fewer articles exist concerning the vocabulary used in libraries to reference their services. In the literature that does exist, the focus is primarily on professional titles. For example, the author's title is Librarian for Advanced Research and Engagement; but her duties encompass a variety of roles, both traditional and new, in the academic library context: reference, outreach, assessment, instruction, collection development, collaboration, and strategy. Thus, along with job titles, library vocabulary should evolve and expand to describe services and convey value to users of all types, beginners to experts.

As librarians experiment with new services and programs to meet changing research practices, marketing becomes increasingly essential. For example, whether attendance at a particular event or usage of a service is due to schedules, awareness, or need is difficult to ascertain. The focus of current research from the Association of Research Libraries (ARL ${ }^{41}$ and Ithaka $\mathrm{S}+\mathrm{R},{ }^{42}$ among others, has been service need; and the focus of forthcoming research from UCLA Library is an examination of the local circumstances and context. ${ }^{43}$ Even though schedules will always be a challenge in the busy lives of students and faculty, libraries can increase awareness through effective marketing campaigns. Recent efforts in this arena at UCLA have been only intermittently successful, however. As a result, the author began to question the vocabulary used to talk about what libraries provide and the value they convey to the community. She decided to evaluate the terminology commonly used in libraries, using UCLA as a case study. The objective of this study was to employ the vignettes method to identify a preferred, user-centered vocabulary for marketing and describing library services to students, faculty, staff, and campus administrators. What words would patrons use to describe the services that libraries provide?

Methodology Rationale. The author originally considered a card-sorting methodology to investigate this research question. After consultation with Greg Guest, an expert in qualitative and quantitative research methods and an instructor at the previously-mentioned IRDL, ${ }^{44}$ she determined that the focus group and vignettes model as described by Fleming and Stalker ${ }^{45}$ would allow a more nuanced interpretation of the concepts of services the library offers and avoid the further use of jargon that would occur if she tried to describe the services rather than the users' needs. With the vignettes method, the author could present an abstract situation (different people needing various types of help) with the least amount of bias or preconception to influence participants' responses. Vignettes would also allow respondents to envision needs apart from their own through the description of an invented scholar. Furthermore, because the research goal was to identify terminology appealing to a variety of users, purely creative marketing name-generating techniques might result in catchy words rather than terms that would be universally understood.

Procedures and Design. The author constructed fifteen short vignettes to illustrate faculty and student needs that the library has services to support. In the vignettes, she tried to capture a range of library user roles (such as researcher, teacher, writer, student doing first research assignment). The bases for these vignettes were common interactions with students and faculty in public services, queries received via e-mail, and exchanges with colleagues. These vignettes were then tested with students and colleagues and edited based on their feedback. Because this research involved human subjects, the study was reviewed and approved by the campus's IRB.

The author conducted five focus groups, ranging in size from three to nine participants and containing a mix of graduate and undergraduate students from a variety of disciplines. (The intended group size of eight to twelve was not always achieved due to illness and no-shows.) She used campus listservs to recruit participants via e-mail. 
Members of each focus group received fifteen vignettes, each printed on a separate sheet of paper. For each vignette, members individually brainstormed words or phrases illustrating the service presented and wrote them on the paper. Then members shared the terms aloud with the group. A facilitator (the author, in this case) recorded all suggested terms on a large Post-it. Once all options were recorded, the facilitator asked participants to discuss them and indicate which most effectively represented the concept. The group repeated this process for each vignette. The facilitator recorded the group's top choice(s) on a master sheet at the conclusion of the session. After discussing all of the vignettes, participants gave general feedback about the exercise and shared their thoughts on what would be most successful in marketing library services and resources.

The author compiled a list of preferred terms from all the groups for use in an online questionnaire to test the preferences of the focus groups against a larger, more representative sample of the UCLA community, including faculty and staff who are less likely to have time to participate in focus groups. The questionnaire contains the same vignettes but with multiple-choice answers, including the current term the library used to describe the service, where applicable, and encompasses both exploratory and predictive vignette methods. This survey was sent to a stratified, random sample of UCLA community members to determine which terms are most favored and to identify any differences based on disciplinary focus or degree of research experience.

The following are two of the vignettes used in the study.

1. Harrison is a sophomore, and it's getting close to the end of the quarter. He has his first big research paper due soon and wants to make sure he is looking in the right places for information to support his argument. He also wants to make sure that he is doing the bibliography correctly.

2. Joanne is a researcher in a chemistry lab and is applying for grant funding through the National Institutes of Health. She's heard about federal requirements regarding how she collects her data but needs some help understanding what she has to do.

Q. What types of help do these persons need? What should they be looking for, either online or in the library building?

Results. The results from the survey confirmed and enhanced my observations from the focus groups. With 367 valid responses from students, faculty, and staff representing the range of academic disciplines on campus, the use of vignettes in a survey with controlled responses allowed for some interesting insights. Although respondents did not identify a single, preferred option for each vignette, as originally hoped, their choices indicate some general trends in user preference, from which one can make recommendations for marketing library services. For example, users preferred terminology that was specific to their research need. They were not looking for general help; and, in any vignette that included "reference desk" as a possible response, it was the least likely to be selected, except for one vignette in which "special collections 101" was the least-preferred. Furthermore, survey responses indicate a preference for independence and self-sufficiency; that is to say, the most popular choices suggest solutions to the scenario that do not require asking a person for help (such as "navigating databases," "how to access public records," and "organizing references"). Taken together, these trends highlight the need for libraries to market their services to specific audiences with language that indicates the breadth of expertise available.

Reflections. The use of vignettes with focus groups allowed participants to think about the situation of the person depicted and about what he or she might do in the situation without the pressure of providing the "correct answer." The vignettes also served to avoid the introduction of bias in the form of terminology the library already 
uses for the services depicted, although some students were familiar with library terminology because they had used our services prior to the study. Vignettes in a survey with the multiple-choice response options still offered the depersonalized frame of mind, but it focused the scope of the choices to something that could be analyzed quantitatively for patterns.

Although overall the methodology worked well, the author did face some challenges, especially in the focus groups. First, some students' realm of experience did not include a solid understanding of high-level or advanced research situations or practices. For example, some undergraduates had difficulty suggesting words or phrases for vignettes depicting faculty with publishing and research data questions. Second, students took some time to get into the activity, a challenge that was fairly consistent across the groups; each group's working style and dynamics flowed better after the first two or three vignettes. Although the sessions included a warm-up activity with introductions, it was apparently not sufficient. Therefore, the author recommends scheduling time for a more thorough warm-up, perhaps involving some practice vignettes. Third, during the first couple of vignettes, the author occasionally had to reiterate the directions, signaling that the participants were not entirely clear about what they were to do. Fourth, some students were more hesitant about participating than others. To encourage them, the author tried calling on those who had not had a chance to talk, as a moderator of a nonvignette focus group might do. Fifth, when participants were asked to narrow the options to select the best choice of words, they seemed reluctant to pick a single option. This could have been the result of discomfort at judging a peer's contribution to be inferior, because they did not have strong feelings one way or the other, or because they felt a complex topic cannot really have one best option. The survey results were useful in providing further information about preferences by patron type and disciplinary area.

Managing the time and energy in a room in which multiple people are reading a set of texts posed another challenge. Participants read at different paces and, because each vignette presented different characters, they had to change their frame of mind for each scenario. In an attempt to account for different reading speeds, participants worked on blocks of three vignettes at a time rather than stopping to talk after each one. Proceeding one vignette at a time might have eliminated the longer pauses but might also have placed the slower readers at a greater disadvantage or made them feel more awkward. The author did suggest that anyone finishing early could read ahead and make notes. Had the vignettes involved only three or four characters with different situations of need, discussion might have flowed more continuously. However, opting for the different characters seemed the only way to represent the diverse UCLA population.

Due to scheduling and time constraints, the author had to cut the total number of vignettes from twenty to fifteen, thus eliminating scenarios and services about which it would have been nice to obtain data. Nevertheless, the information concerning those that were included, along with the general feedback at the end of the sessions and combined with the survey responses, provides actionable recommendations to help librarians to better market services, and which could be applied to services not specifically examined in the study. The framework of vignettes with focus groups and a survey achieved results that would have been far more difficult via alternative methods. The vignettes provided the realistic but depersonalized situations and facilitated discussion and selection of preferred terminology. The focus groups allowed for brainstorming and creativity, and the survey results showed that, for some vignettes, faculty and graduate students had different preferences from those of undergraduates. Focus groups alone would not have enabled analysis by patron type (nor provided 
faculty responses). Also, given the disinclination of the group participants to pick a single favorite term, a more objective method was needed to find some consensus and identify trends.

\section{Discussion}

Although the two examples above examined very different research questions, both authors selected the vignette method because it allowed them to create hypothetical scenarios to depersonalize sensitive topics and stimulate discussions. They also experienced similar challenges implementing this method. Both authors noted that the student participants struggled to shift from thinking about one vignette's character to another, each offering suggestions about how to minimize this in future studies. While one of the strengths of the vignette method is the opportunity it presents for participants to adopt an alternate persona, the challenge of adopting multiple points of view within one session should give future researchers pause to carefully consider the design and flow of the experiment. More background information or other cues may be necessary to provide adequate context for participants to shift frames of thinking. Even when the character of the vignette remained the same, participants had noticeable difficulty shifting focus from one aspect of the story to the next. Researchers should allow enough time for testing and revising vignettes in the early stages of their projects to minimize this difficulty.

These two examples differed in their administration of the vignettes-one used in-depth interviews; the other, focus groups and a questionnaire. The results show vignettes to be effective in all three uses. The research question and desired population sample are the keys to determining which use of vignettes is better suited to a particular situation. Example 1 chose the in-depth interviews to cover as much ground as possible (all six concepts within the ACRL Framework) in the least amount of time. Interviewing individual participants also allowed for the possibility of discussing sensitive topics like procrastination, plagiarism, and "cutting corners" in academic research without the risk of participants resorting to socially mitigated responses. Example 2 used focus groups to enable brainstorming and the added creativity sparked by working in a team, as well as to get a larger sample of the population. And the survey/questionnaire was selected to test the output of the brainstorming sessions with an even larger and more representative population sample. As other researchers consider using the vignettes method, they should consider the scope of their research questions, their desired population/sample sizes, and also the resources available to them. Analysis of individual interviews usually requires transcription and coding. This is also true of focus groups, although in this particular example the research question did not require it.

Both examples revealed interesting insights into behaviors and preferences of library patrons that would have been difficult to gain through other means. It is unlikely that a student who was asked directly about threshold concepts would have provided the types of responses elicited by the vignettes, especially with regard to questions about how students conduct research, how they access research materials, and how they value their work and the work of their classmates. And vignettes that illustrated a variety of user types and needs helped respondents to consider points of view beyond their own and to suggest language of broader appeal. The results from the first example most clearly demonstrated the vignette methodology's effectiveness in creating empathy for the represented character. The author noted that, in comparison to interviews he had conducted previously, the participants were far more likely to ask questions about the motivation of the character - why he or she did one thing or another.

As stated at the beginning of this article, vignettes (via the engagement of hypothetical scenarios) serve as a valuable research tool to study people's lives, perceptions, 
beliefs, attitudes, and meanings about specific situations. As shown through the two case studies, LIS researchers who seek to tackle abstract concepts and situations can benefit from using vignettes. Researchers studying sensitive or difficult topics, such as copyright and plagiarism, might also consider vignettes because the depersonalization of the hypothetical scenarios allows study participants to distance themselves from the topic and to be less likely to succumb to the influence of socially desirable responses.

Vignettes can be used to assess the behaviors, attitudes, and perceptions of both students and faculty. Future LIS researchers could also use the methodology to assess user attitudes toward specific library services, collections, programs, and staff or to assess a campus community's general attitude toward the library. It would be interesting, for example, to compare user attitudes about a specific library on a specific campus and those same user attitudes toward libraries in general. Vignettes offer an ideal methodology for this very project: it is both personal and depersonalized, allowing researchers to probe and identify implicit biases, assumptions, and attitudes.

Vignettes could assist library administrators to formulate strategic plans based on user expectations of the library's role on campus. Depending on the target audience (in the case of faculty and researchers, for example), common scenarios of academic choices and behaviors around publishing, open access, or data visualization could be presented to users to better understand their motivations in those situations and where they are most in need of assistance. This could help the library to prioritize staffing and services. For more student-centered services and behaviors, vignettes could address writing papers, their workload, and type of work required at what point.

To help librarians and researchers further explore the use of vignettes, a list of possible vignette applications in LIS research is developed and shown in table 1.

\begin{tabular}{|l|l|}
\hline \multicolumn{2}{|c|}{ Potential Use of Vignettes in LIS Research } \\
\hline \multicolumn{1}{|c|}{ Research Topic } & \multicolumn{1}{c|}{ Possible Vignettes } \\
\hline $\begin{array}{l}\text { How do faculty make decisions in } \\
\text { publishing in open access journals? }\end{array}$ & $\begin{array}{l}\text { A faculty member decides where to publish } \\
\text { a paper, choosing between a traditional } \\
\text { journal and an open access journal. }\end{array}$ \\
\hline $\begin{array}{l}\text { When do students feel it is OK to } \\
\text { plagiarize? }\end{array}$ & $\begin{array}{l}\text { Various examples of students working on } \\
\text { college-level assignments: writing under a } \\
\text { deadline, a creative/derivative work, or a } \\
\text { summary of a class discussion. }\end{array}$ \\
\hline $\begin{array}{l}\text { How do faculty decide what texts to } \\
\text { assign? How often do they evaluate their } \\
\text { syllabi? Do they think about how to best } \\
\text { engage with the library while designing } \\
\text { assignments? }\end{array}$ & $\begin{array}{l}\text { A story about creating new courses or } \\
\text { adapting existing courses to new contexts } \\
\text { (such as new student population, limited } \\
\text { budget). }\end{array}$ \\
\hline $\begin{array}{l}\text { How does a library spend its capital } \\
\text { expenditures? }\end{array}$ & $\begin{array}{l}\text { A new person has just been hired to manage } \\
\text { the library's budget and finances and } \\
\text { needs to make budgetary decisions when } \\
\text { confronted with problems X, Y, and Z. }\end{array}$ \\
\hline $\begin{array}{l}\text { What do library administrators expect } \\
\text { of librarians working toward promotion/ } \\
\text { tenure? }\end{array}$ & $\begin{array}{l}\text { Examples of librarians at various levels, } \\
\text { working strictly within a 40-hour week vs. } \\
\text { spending time after hours and on weekends; } \\
\text { noncaretaker librarians vs. those with } \\
\text { families/caretaker responsibilities. }\end{array}$ \\
\hline
\end{tabular}




\section{Conclusion}

Through the general introduction of vignettes and the discussion of its use in two LIS research studies, we have presented a comprehensive depiction of this methodological tool as well as its potential in expanding and diversifying the repertoire of LIS research methods. Halpern et al. called for more diverse research methods in LIS research, stating that limited research methods impose "excessive limitations on what we can know about our field and our users." 46 To enhance the quality and rigor of LIS research, we must continuously embrace new methodological approaches and investigate research problems from new angles.

We believe vignettes are a methodological choice worthy of exploration and consideration in LIS research. We expect this paper to serve as a starting point for researchers in their development of an in-depth understanding of this method and its application. In the future, we hope to see more studies involving the use of vignettes to investigate various LIS research problems and more researchers joining the vignettes-related methodological discourse.

\section{Acknowledgements}

We wish to extend our gratitude to the project directors of the Institute for Research Design in Librarianship (IRDL), Kristine Brancolini and Marie Kennedy; the instructors, Greg Guest and Michael Stephens; the wonderful cohort of IRDL 2014; and our colleague Emily.

\section{Notes}

1. Janet Finch, “The Vignette Technique in Survey Research,” Sociology 21, no. 1 (1987): 105.

2. Michael Bloor and Fiona Wood, Keywords in Qualitative Methods: A Vocabulary of Research Concepts (London: Sage, 2006); Paul Fleming and Michael Stalker, "In Focus: Using Vignettes in Public Health Research," in Public Health Research Methods, eds. Greg Guest and Emily Namey (Thousand Oaks, Calif.: Sage, 2015), 611-14.

3. Fleming and Stalker, "In Focus."

4. Finch, "The Vignette Technique."

5. Gillian Benderlow, "Using Visual Imagery to Explore Gendered Notions of Pain," in Researching Sensitive Topics, eds. Claire M. Renzetti and Raymond M. Lee (London: Sage, 1993), 221-28.

6. Brian McKinstry, "Do Patients Wish to Be Involved in Decision Making in the Consultation? A Cross-Sectional Survey with Video Vignettes," British Medical Journal 321 (2000): 867-71.

7. N. Jenkins, "More than Skin Deep? A Study of Young People's Leisure Injuries" (PhD diss, Cardiff University, 2006).

8. Angelo Kinicki, Peter W. Hom, Melanie R. Trost, and Kim J. Wade, "Effects of Category Prototypes on Performance-Rating Accuracy," Journal of Applied Psychology 80 (1995): 354-70; L. Anthony Loman and William E. Larkin, "Rejection of the Mentally Ill: An Experiment in Labeling," Sociological Quarterly 17 (1976): 555-60.

9. Finch, "The Vignette Technique."

10. Jan Fischer, Nick Jenkins, Michael Bloor, Joanne Neale, and Lee Berney, Drug User Involvement in Treatment Decisions (New York: Joseph Rowntree Foundation, 2007).

11. Nick Jenkins, Michael Bloor, Jan Fischer, Lee Berney, and Joanne Neale, "Putting It in Context: The Use of Vignettes in Qualitative Interviewing," Qualitative Research 10, no. 2 (2010): 175-98.

12. Fleming and Stalker, "In Focus."

13. Jenkins et al., "Putting It in Context."

14. Fleming and Stalker, "In Focus."

15. Fleming and Stalker, "In Focus"; Lisa Wallander, "25 Years of Factorial Surveys in Sociology: A Review," Social Science Research 38 (2009): 505-20.

16. Christine Barter and Emma Renold, "The Use of Vignettes in Qualitative Research," Social Research Update 25 (1999): 1-4; Rhidian Hughes and Meg Huby, "The Application of Vignettes in Social and Nursing Research," Journal of Advanced Nursing 37, no. 4 (2002): 382-86. 
17. Nancy E. Schoenberg and Hege Ravdal, "Using Vignettes in Awareness and Attitudinal Research," International Journal of Social Research Methodology 3, no. 1 (2000): 63-74.

18. Hughes and Huby, "The Application of Vignettes."

19. Rhidian Hughes, "Considering the Vignette Technique and Its Application to a Study of Drug Injecting and HIV Risk and Safer Behaviour," Sociology of Health E Illness 20, no. 3 (1998): 381-400; Jenkins et al., "Putting It in Context"; Naila Rahman, "Caregivers' Sensitivity to Conflict: The Use of the Vignette Methodology," Journal of Elder Abuse E Neglect 8, no. 1 (1996): 35-47.

20. Finch, "The Vignette Technique"; Erving Goffman, Where the Action Is: Three Essays (London: Allen Lane/Penguin Press, 1969); Jenkins et al., "Putting It in Context."

21. Finch, "The Vignette Technique," 109.

22. Jenkins et al., "Putting It in Context."

23. Finch, "The Vignette Technique."

24. Hughes and Huby, "The Application of Vignettes."

25. Melville J. Herskovits, "The Hypothetical Situation: A Technique of Field Research," Southwestern Journal of Anthropology 6 (1950): 32-40.

26. Harold H. Anderson and G.L. Anderson, An Introduction to Projective Techniques and Other Devices for Understanding Human Behavior (Englewood Cliffs, N.J.: Prentice Hall, 1951).

27. Finch, "The Vignette Technique."

28. Dinah Gould, "Using Vignettes to Collect Data for Nursing Research Studies: How Valid Are the Findings?" Journal of Clinical Nursing 5 (1996): 207-12.

29. Christine Urquhart and Sophie Crane, "Nurses' Information-Seeking Skills and Perceptions of Information Sources: Assessment Using Vignettes," Journal of Information Science 20, no. 4 (1994): 234-46.

30. Elizabeth Connor, "Using Clinical Vignette Assignments to Teach Medical Informatics," Medical Reference Services Quarterly 22, no. 4 (2003): 31-44.

31. Graham R. Walden, "Informing Library Research with Focus Groups," Library Management 35 (2014): 558-64.

32. Robert Detmering and Anna Marie Johnson, "Research Papers Have Always Seemed Very Daunting: Information Literacy Narratives and the Student Research Experience," portal: Libraries and the Academy 12, no. 1 (2012): 5-22; Philippa Levy and Robert Petrulis, "How Do First-Year University Students Experience Inquiry and Research, and What Are the Implications for the Practice of Inquiry-Based Learning?" Studies in Higher Education 37, no. 1 (2012): 85-101; Jan H.F. Meyer, Martin P. Shanahan, and Rüdiger C. Laugksch, "Students' Conceptions of Research. I: A Qualitative and Quantitative Analysis," Scandinavian Journal of Educational Research 49, no. 3 (2005): 225-44.

33. Steve O'Conner and Lai-chong Au, "Steering a Future through Scenarios: Into the Academic Library of the Future," Journal of Academic Librarianship 35, no. 1 (2009): 57-64.

34. Association of College and Research Libraries (ACRL), Framework for Information Literacy for Higher Education (Chicago, Ill.: American Library Association, 2015), available online at www.ala. org/acrl/sites/ala.org.acrl/files/content/issues/infolit/Framework_ILHE.pdf [accessed 15 November 2016].

35. Jan Meyer and Ray Land, Threshold Concepts and Troublesome Knowledge: Linkages to Ways of Thinking and Practicing within the Disciplines (ETL Project Occasional Report 4, 2003), available online at www.etl.tla.ed.ac.uk/docs/ETLreport4.pdf [accessed 15 November 2016].

36. Librarians interested in learning more about this approach to information literacy should consult the ACRL Annotated Bibliography of Threshold Concepts, available online at www.ala.org/ acrl/issues/infolit/teaching/thresholdbib [accessed 15 November 2016].

37. Rebecca Halpern, Christopher Eaker, John Jackson, and Daina Bouquin, “\#DitchTheSurvey: Expanding Methodological Diversity in LIS Research," In the Library with the Lead Pipe (March 11, 2015), available online at www.inthelibrarywiththeleadpipe.org/2015/ditchthesurvey-expandingmethodological-diversity-in-lis-research/ [accessed 15 November 2016].

38. Greg Guest, personal communication, 2014.

39. Greg Guest, Emily Namey, and Marilyn Mitchell, Collecting Qualitative Data: A Field Manual for Applied Research (London: Sage, 2013).

40. Jocelyn A. Rankin, Suzanne F. Grefsheim, and Candace C. Canto, "The Emerging Informationist Specialty: A Systematic Review of the Literature," Journal of the Medical Library Association 96, no. 3 (2008): 194-206.

41. Lucinda Covert-Vail and Scott Collard, New Roles for New Times: Research Library Services for Graduate Students (Chicago, Ill.: Association of Research Libraries, 2012).

42. Michael Long and Roger Schonfeld, "Ithaka S+R US Library Survey 2013," Ithaka S+R, available online at http://www.sr.ithaka.org/wp-content/uploads/2015/08/SR_LibraryReport_20140310_0.pdf [last modified 11 March 2014]; Jennifer Rutner and Roger C. Schonfeld, "Supporting the Changing Research Practices of Historians," Final Report from ITHAKA S+R 
(December 10, 2012).

43. The North Campus Research Community Study for which the author is the project manager has just completed data collection and is working on analysis. Preliminary findings have been presented in several conferences, including ACRL, available online at www.ala.org/acrl/sites/ala. org.acrl/files/content/conferences/confsandpreconfs/2013/papers/Brunner_etal_Transformation. pdf [accessed 15 November 2016].

44. Greg Guest, personal communication, 2014.

45. Fleming and Stalker, "In Focus."

46. Halpern et al., "\#DitchTheSurvey." 